\title{
Bacteriological Profile of Neonatal Sepsis in a Tertiary Hospital in Bangladesh
}

\author{
S BEGUM ${ }^{\mathrm{a}}$, MA BAKI ${ }^{\mathrm{b}}$, GK KUNDU' ${ }^{\mathrm{c}}$, I ISLAM ${ }^{\mathrm{d}}$, M KUMAR ${ }^{\mathrm{e}}, \mathrm{A} \mathrm{HAQUE}^{\mathrm{f}}$
}

\begin{abstract}
Summary:
Objectives: To evaluate the common pathogens associated with neonatal sepsis in a tertiary care hospital in Bangladesh and their antibiotic susceptibility pattern.
\end{abstract}

Materials and Method: This prospective study was done at Special Care Baby Unit (SCABU) BIRDEM Hospital from January to December 2008. Neonates whose blood culture yielded growth of bacteria were included in this study.

Results: Sepsis was associated with Low Birth Weight and common organism isolated was Klebsiella and Enterobacter.

\section{Introduction:}

Neonatal Sepsis is the commonest cause of neonatal mortality and it is responsible for $30-50 \%$ of the total neonatal deaths in developing countries ${ }^{1,2}$. It is estimated that $20 \%$ of neonates develop sepsis and approximately $1 \%$ death related to sepsis ${ }^{2}$. Some of the factors responsible for sepsis in newborns are immaturity of the immune system, which include decreased

a. Dr. Suraiya Begum, FCPS, Assistant Professor, Department of Paediatrics, Bangabandhu Sheikh Mujib Medical University, Dhaka.

b. Dr. Md. Abdul Baki, MD, Neonatology, Registrar, Department of Paediatrics, BIRDEM Hospital, Dhaka.

c. Dr. Gopen Kumar Kundu, FCPS, Assistant Professor, Department of Paediatrics, Bangabandhu Sheikh Mujib Medical University, Dhaka.

d. Dr. Imnul Islam, Assistant Professor, Department of Paediatrics, Bangabandhu Sheikh Mujib Medical University, Dhaka.

e. Dr. Manik Kumar Talukdar, Assistant Professor, Department of Paediatrics, Bangabandhu Sheikh Mujib Medical University, Dhaka.

f. Dr. Afroza Haque, FCPS, Registrar, Department of Paediatrics, BIRDEM Hospital, Dhaka.

Address of Correspondence: Dr. Suraiya Begum, FCPS, Assistant Professor, Department of Paediatrics, Bangabandhu Sheikh Mujib Medical University, Dhaka, Cell Phone: 01715-131535, E-mail: suraiyardr07@yahoo.com

Received: 02 March, 2001

Accepted: 13 March, 2012
Ampicillin, Genatamicin and third generation cephalosporin were almost resistance to all organisms.

Conclusion: Bacterial profile is not the same as western countries, Gram-negative bacteria and in particular Klebsiella and enterobacter species are the leading causes of neonatal sepsis and resistance to ampicillin, gentamicin and third generation cephalosporin.

(J Bangladesh Coll Phys Surg 2012; 30: 66-70)

phagocyte activity of white cells, decreased production of cytokines and weak cellular and humoral immunity. Moreover the natural skin barrier is very thin. Various other maternal, foetal and environmental factors also contribute towards sepsis in the newborns. Some of the maternal factors are premature rupture of membrane, maternal fever within 2 weeks prior to delivery, meconium stained amniotic fluid (MSAF), foul smelling liquor and instrumental delivery. The foetal factors include birth weight, gestational age and APGAR score $^{3,4}$. Neonatal sepsis is a life threatening emergency and delay in diagnosis and treatment with appropriate antibiotics may have devastating consequences. Surveillance is needed to identify the common pathogens of the disease as well as the antibiotic susceptibility profile of the pathogens in a particular area. This study was designed to evaluate the common pathogens associated with neonatal septicemia in our hospital and their antibiotic susceptibility pattern over a one year period.

\section{Methods:}

This prospective study was done at Special Care Baby Unit (SCABU) in BIRDEM Hospital from January to December 2008. Neonates whose blood culture yielded growth of bacteria were included in this study. Neonates were categorized in two groups; group-1 included 
preterm and group-2 term neonate. Blood culture samples were aseptically collected by the doctors into the blood culture broth and were sent to the laboratory where they were handled according to the manufacturers specifications. The antibiotic sensitivity tests were carried out by disk diffusion method. All the records of the study population were carefully reviewed and data including sex, age, clinical features consistent with sepsis, results of cultures, antibiotic sensitivity and clinical outcome (death versus survival) of the patients were entered into a data collection sheet. Statistical analyses were calculated by Statistical Package for Social Sciences (SPSS version 12).

\section{Results:}

In this Study total 65 neonates were included whose blood culture were positive. Among them 40 (61.54\%) babies were preterm (group-1) and 25(38.46\%) were term (group-2), and 47(70\%) were LBW. Male was 38 (65\%) and female was 27 (35\%), inborn was about 50\% and majority was delivered by C/S (72.31\%). Sepsis developed within 7 days (early onset) in 23 (35.4) babies (Table-I). Mean birth weight was $1513.02 \pm 423.61 \mathrm{~g}$ in group-1and 2840 ( \pm 640.80$)$ g in group-2.

Majority of neonate presented with feeding intolerance (50.77\%), respiratory distress (40.28\%), abdominal distension (33.85\%), apnoea (24.62\%) and bleeding manifestation (23.08\%). Apnoea, less activity, hyperglycaemia and feeding intolerance were present equally in both group. Abdominal distension and bleeding manifestation were more in group-1 and respiratory distress and convulsion were more common clinical presentation in group-2 (Table-II).

Table-I

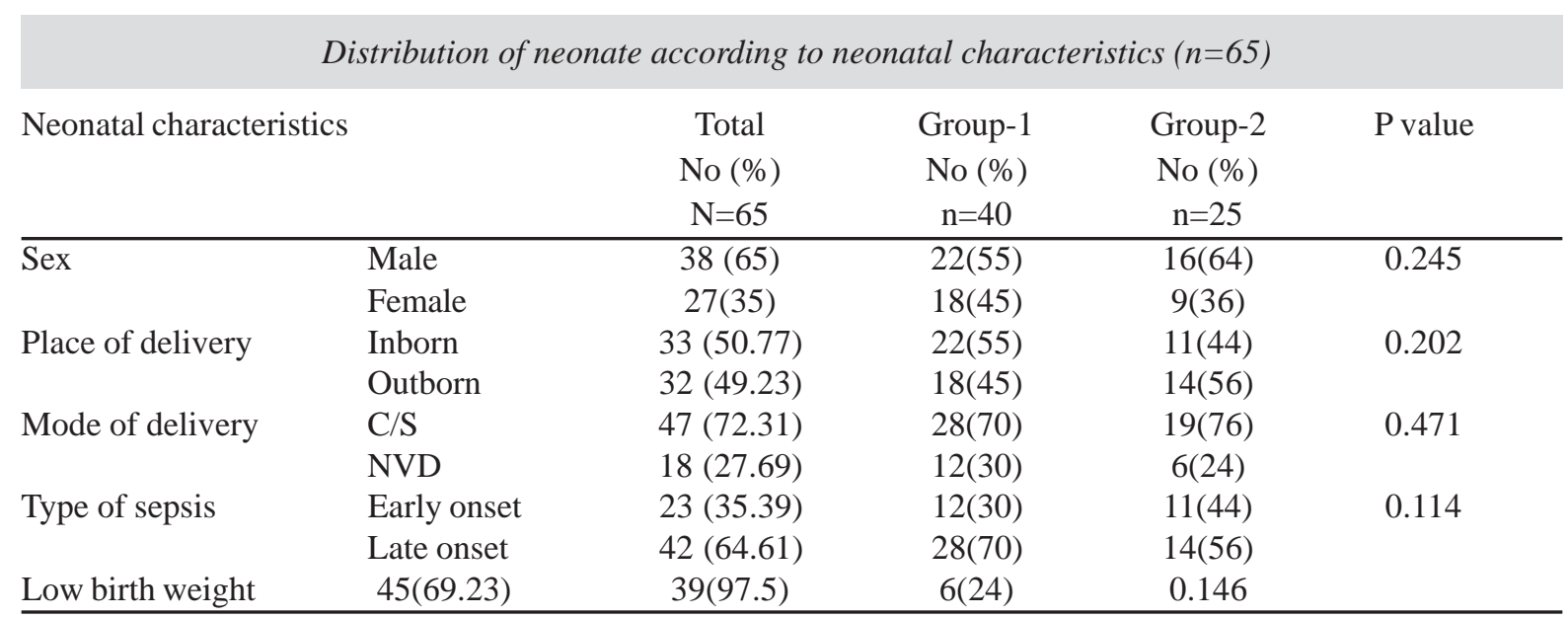

Table-II

\begin{tabular}{lcccc}
\multicolumn{5}{c}{ Distribution of neonate according to clinical feature } \\
Clinical feature & No (\%) & Group-1 No (\%) & Group-2 No (\%) & P value \\
\hline Apnoea & $16(24.62)$ & $09(22.5)$ & $07(28)$ & 0.313 \\
Less active & $21(32.31)$ & $13(32.5)$ & $08(32)$ & 0.486 \\
Feeding intolerance & $33(50.77)$ & $20(50)$ & $13(52)$ & 0.099 \\
Hyperglycemia & $03(4.62)$ & $02(5)$ & $01(4)$ & 0.217 \\
Respiratory distress & $28(40.28)$ & $18(45)$ & $10(64)$ & 0.073 \\
Sclerema & $06(9.23)$ & $04(10)$ & $02(8)$ & 0.411 \\
Bleeding & $15(23.08)$ & $11(27.5)$ & $04(16)$ & 0.153 \\
Abdominal distension & $22(33.85)$ & $16(40)$ & $06(24)$ & 0.001 \\
Convulsion & $13(20.0)$ & $10(25)$ & $03(12)$ & 00.001 \\
\hline
\end{tabular}


In this study $52.3 \%$ neonatal sepsis was caused by Klebsiella species. Second most common cause was Enterobacter (20.0\%). Other organism were Acinatobacter 10.8\%), Pseudomonas (06.2\%), Serratia (06.2\%), Cytobacter (03.1\%). Gram positive organism (Staphylococcus) was found in only one neonate. Sepsis with Klebsiella was found equally in both groups; Acinatobacter, Pseudomonas and Serratia were more common organism in group-2 and Enterobacter was more in group-1 (Table-III).

In this study, both groups were equally sensitive to all antibiotics except chloramphenicol (Table-IV).
Ampicillin and Gentamicin were 100\% resistance to Klebsiella, third generation cephalosporin was also resistance to klebsiella. Imipenem and meropenem were highly sensitive to all organisms and ceftazidime was also highly sensitive to pseudomonas and Serratia (75\%). Amikacin and Netilmycin had good sensitivity against some organism than gentamicin (Table-V). Overall mortality due to sepsis was found 7 (10.8\%) in this study and more in group-1(15\%) than group-2 (4\%) (Table-VI).

Table-III

\begin{tabular}{lccc} 
& Organism isolated from blood culture $(n=65)$ & \\
OrganismNo (\%)N=65 & Group-1 & Group-2 & P value \\
& No (\%) & No (\%) & \\
& $\mathrm{N}=41$ & $13(52)$ & \\
\hline Klebsiella34 (52.3) & $21(52.5)$ & $3(12.0)$ & 0.152 \\
Acinatobacter 07 (10.8) & $4(1.0)$ & $2(8.0)$ & 0.160 \\
Pseudomonas 04 (6.20) & $2(0.5)$ & $2(8.0)$ & 0.176 \\
Serratia04 (6.20) & $2(0.5)$ & $0(0)$ & 0.113 \\
Cytobacter 02 (03.1) & $2(0.5)$ & $0(0)$ & 0.449 \\
Staphylococcus01 (01.5) & $1(0.25)$ & $4(16.0)$ & 0.113 \\
Enterobacter 13 (20.0) & $9(22.5)$ &
\end{tabular}

Table-IV

Distribution of neonate according to sensitivity pattern $(n=65)$

\begin{tabular}{lccc} 
AntibioticNo (\%) & $\begin{array}{c}\text { Group-1 } \\
\text { No (\%) }\end{array}$ & $\begin{array}{c}\text { Group-2 } \\
\text { No (\%) }\end{array}$ & P value \\
\hline Ampicillin & $02(5.0)$ & $2(8)$ & 0.327 \\
Gentamycin & $5(6.5)$ & $2(8)$ & 0.306 \\
Ceftazidime & $6(15)$ & $4(16)$ & 0.453 \\
Ciprifloxcin & $9(22.5)$ & $8(32)$ & 0.207 \\
Amikacin & $10(25)$ & $5(20)$ & \\
0.332 & & & 0.307 \\
Imipenem & $34(85)$ & $20(80)$ & 0.453 \\
Meropenem & $34(85)$ & $21(84)$ & 0.096 \\
Cotrimoxazole & $6(15)$ & $1(4)$ & 0.447 \\
Netilmycin & $7(17.5)$ & $4(16)$ & 0.087 \\
Chloranphenicol & $1(2.5)$ & $3(12)$ & \\
\hline
\end{tabular}




\section{Table-V}

\begin{tabular}{|c|c|c|c|c|c|c|c|}
\hline \multicolumn{8}{|c|}{$\begin{array}{l}\text { Pattern of antimicrobial sensitivity of microorga nism isolated from blood cultures } \\
\text { of neonates with bacterial sepsis }(n=65)\end{array}$} \\
\hline Antibiotics & $\begin{array}{l}\text { Klebsie-lla } \\
\qquad \begin{array}{c}(\mathrm{n}=34) \\
\mathrm{N}(\%)\end{array}\end{array}$ & $\begin{array}{l}\text { Entero-bactor } \\
\qquad(\mathrm{n}=13) \\
\mathrm{N}(\%)\end{array}$ & $\begin{array}{l}\text { Acinatobactor } \\
\qquad \begin{array}{c}(\mathrm{n}=07) \\
\mathrm{N}(\%)\end{array}\end{array}$ & $\begin{array}{l}\text { Pseudomonas } \\
\qquad \begin{array}{c}(n=04) \\
N(\%)\end{array}\end{array}$ & 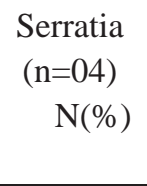 & $\begin{array}{l}\text { Cytobactor } \\
\qquad \begin{array}{c}(n=02) \\
N(\%)\end{array}\end{array}$ & $\begin{array}{c}\text { Staphylo- } \\
\text { coccus } \\
(n=01) \\
N(\%)\end{array}$ \\
\hline Ampicillin & 0 & $02(15.4)$ & 0 & $02(50.0)$ & 0 & 0 & 0 \\
\hline Gentamicin & 0 & 01(07.7) & $04(57.1)$ & $01(25.0)$ & $01(25.0)$ & 0 & 0 \\
\hline Amikacin & 01(02.9) & 0 6(42.9) & $03(42.9)$ & $01(25.0)$ & $03(75.0)$ & $02(100)$ & 0 \\
\hline Imipenem & $30(88.2)$ & $11(84.6)$ & $04(57.1)$ & $03(75.0)$ & $03(75.0)$ & $02(100)$ & $01(100)$ \\
\hline Meropenem & $31(91.2)$ & $11(84.6)$ & $04(57.1)$ & $03(75.0)$ & $03(75.0)$ & $02(100)$ & $01(100)$ \\
\hline Netilmycin & 01(02.9) & $04(30.8)$ & $04(57.1)$ & 0 & 0 & $01(50)$ & $01(100)$ \\
\hline Ceftazidim & 0 & $01(07.7)$ & 03 (42.9) & 03 (75.0) & $03(75.0)$ & 0 & 0 \\
\hline Cefotaxim & 02(05.8) & $01(07.7$ & $04(57.1)$ & $01(25.0)$ & 0 & 0 & 0 \\
\hline Ciprofloxac & $11(32.4)$ & $03(23.1)$ & $02(28.6)$ & $01(25.0)$ & 0 & 0 & 0 \\
\hline
\end{tabular}

\section{Table-VI}

\begin{tabular}{lcccc} 
& \multicolumn{2}{c}{ Distribution of neonate according to outcome $(n=65)$} \\
Outcome & no(\%) & Group-1no(\%) & Group-2no(\%) & P value \\
\hline Survived & $58(89.23)$ & $34((85.0)$ & $24(96.0)$ & 0.096 \\
Died & $7(10.77)$ & $6(15)$ & $1(4)$ & \\
\hline
\end{tabular}

\section{Discussion:}

Sepsis is the commonest cause of neonatal morbidity and mortality. LBW is a strong risk factor contributing to sepsis. In this study birth weight is related to development of sepsis. Among 65 babies who develop neonatal sepsis during the study period $70 \%$ were LBW. This is in concordance with other studies where low birth was found to be important risk factor for sepsis 5,6. LBW babies are mostly also premature and are predisposed to sepsis due to multiple reasons like immune incompetence at various levels of defense, more subjected to invasive interventions etc.

In the present study majority of neonates presented with feeding intolerance (50.77\%), respiratory distress (40.28\%), abdominal distension (33.85\%), apnoea (24.62\%) and convulsion (23.08\%). In a study done in the tertiary care center in Bangladesh poor feeding, respiratory distress and fever was reported in $22.2 \%$, $27.8 \%$ and $44.4 \%$ cases respectively ${ }^{7}$. In the same study they documented hypothermia in $11.1 \%$, apnea in $16.7 \%$, cyanosis in $11.1 \%$, convulsions in $11.1 \%$ and jaundice in $50 \%$.

In our study the most common etiologic agent was Klebsiella. This is in contrast to reports from other parts of the world. In western countries, group B Streptococci and E.coli were the most common Gram-positive and Gram-negative microorganism respectively ${ }^{8,9}$. In our study $52.3 \%$ of neonatal sepses were caused by Klebsiella. All the isolated Klebsiella species were resistant to ampicillin and gentamicic. In a study performed on 124 blood culture-positive neonates with sepsis at neonatal ward of Ali Asghar's Children Hospital; the most common pathogens were Enterobacte (27\%), Staphyloccocus aureus (23\%) and Klebsiella (24\%), respectively ${ }^{10}$. In that study almost all Gram negative bacteria were resistant to ampicillin. In another study in Iran on 242 neonates, Staphylococus aureus was the leading cause of neonatal sepsis and Klebsiella 
was found to be the third most common etiologic agent ${ }^{11}$. Missallati et al reviewed 36 cases of blood-cultureproven neonatal septicemia. They found Klebsiella as the most common microorganism ${ }^{12}$. In their study, similar to ours, the bacterial isolates were resistant to ampicillin. However, they reported sensitivity of the isolates to cefotaxim but in this study only $4 \%$ klebsiella was sensitive to cefotaxim and all were resistant to ceftazidim. Enterobacter infections are emerging as significant pathogens among cases of neonatal sepsis. In this study $2^{\text {nd }}$ most common organism responsible for neonatal sepsis was Enterobacter. Bhutta in his study found $10 \%$ neonate developed sepsis with Enterobacter. Approximately half (47\%) of Enterobacter infections presented within 72 hour of birth and the associated mortality was $21 \%$. Increasing resistance to commonly used first- and second-line antibiotics over the last five years was noted ${ }^{13}$.

Acinetobacter can be a cause for concern in neonatal units. It may be associated with severe complications like bleeding diathesis, NEC, meningitis and hyperbilirubinemia with consequent high mortality ${ }^{14}$. In that study $10.8 \%$ neonatal sepsis are due to acinatobacter. Misra A found acinatobacter was responsible for neonatal sepsis in $31.0 \%$ baby. This high number in their study was due to increase outbreak of Acinatobacter sepsis in that period.

In summary our bacterial profile was not the same as western countries, Gram-negative bacteria and in particular Klebsiella and enterobacter species were the leading causes of neonatal sepsis. However the prevalence of resistant klebsiella spp. was significant and deserves more consideration. We reviewed the prevalence of various etiologic agents in a one year period. We showed that our bacterial profile was not the same as western countries, Gram-negative bacteria and in particular Klebsiella and enterobacter species were the leading causes of neonatal sepsis and almost all were resistance to ampicillin, gentamicin and third generation cephalosporin.

\section{References:}

1. Bang AT, Bang RA, Bactule SB, Reddy HM, Deshmukh MD. Effect of home-based neonatal care and management of sepsis on neonatal mortality: field trial in rural India. Lancet 1999; 354:1955-61.

2. Chacko B, Sohi I. Early Onset Neonatal Sepsis. Indian Journal of Pediatrics. January 2005; 72:23.

3. Távora AF,. Castro AB, Militão MA, Girão JE et al. Risk Factors for Nosocomial Infection in a Brazilian Neonatal Intensive Care Unit. The Brazilian Journal of Infectious Diseases 2008;12(1):75-79.

4. Stoll BJ. The global impact of neonatal infection. Clin Perinatol 1997; 24:1-21.

5. Khinchi YR, Shreshta D, Sarmah BK et al. A study of morbidity and mortality profile of neonates admitted in tertiary care hospital in central Nepal. Journal of College of Medical Sciences, Nepal, 2008; 5: 70-5.

6. Jeeva Sankar M, Agrawal R, Deorari AK et al. Sepsis in newborn. Indian J Pediatr 2008; 75: 261-66.

7. Ahmed NU, Chowdhary A, Hoque M et al. Clinical and bacteriological profile of neonatal septicemia in a tertiary level pediatric hospital in Bangladesh. Indian Pediatrics 2002; 39: 1034-39.

8. Stoll BJ. Infections of the neonatal infant. In: Behrman RE, Kleigman RM, Jenson HB, editors. Nelson Textbook of Pediatrics. Philadelphia:W.B.Saunders, 18th ed, 2008 p. 62339.

9. Weinberg GA, Powell KR (2001). Laboratoty aids for the diagnosis of neonatal sepsis.In: Infectious diseases of the fetus and newborn infant. Eds, Remington JS, Klein JO, Philadelphia: W. B. Saunders, 5th ed. p. 1327-44.

10. Samaie H. Bacterial pathogens and pattern of antibiotic sensitivity in neonatal sepsis. Journal of Iranian Medical Council, 1997; 15(4):151-54.

11. Ghadamli P. A review of bacterial pathogens of neonatal sepsis at hospitals of Shahid Beheshti University during the period between 1992-1997. Journal of Qazvin University of Medical Sciences, 1998; 2(6-7):53-7.

12. Misallati A, El-Bargathy S, Shembesh N. Blood-cultureproven neonatal septicemia: a review of 36 cases. East Mediterr Health, 2000;( 2-3): 483-86.

13. Bhutta ZA. Enterobacter sepsis in the newborn—a growing problem in Karachi. The Journal of Hospital Infection.1996;34(3):211-6.

14. Mishra A, Mishra S, Jaganath G Mittal RK, Gupt PK. Acinatobacter Sepsis in Newborns. Indian Pediatrics. January 1998; 35: 27-3. 